\title{
The Influence of Value Clarification Technique Learning Models Online Based on Afective Learning Outcomes in Historical Learning
}

\author{
Restu Yanuar Ula, Sarkadi, Aip Badrujaman \\ Universitas Negeri Jakarta
}

yanuarularestu@gmail.com

\section{Article History}

accepted 1/09/2020

approved 4/10/2020

published $1 / 12 / 2020$

\begin{abstract}
The improvement of the quality of education is based on the establishment of the quality of learning and the development of technology. The quality of learning is determined by the competence of teachers in managing the classroom. Online learning with various features and applications can be a great alternative for teachers and students to keep interacting without having to come face to face during covid-19. The online-based VCT learning model can provide critical-creative power, fostering positive attitudes, interests, and grades to students in history learning. Therefore, the purpose of this study is to determine the influence of the online-based Value Clarification Technique learning model on the affective learning outcomes of history students. The research method uses quantitative methods with quasi-experimental designs. The population in this study is all grade XI students of Sma Negeri 9 Bogor City. While the sampling technique is purposive sampling which is divided into two classes into experiment groups (XI IPA 3) and control group (XI IPA 1). The data collection method is a multiple-choice test method. The results of this study show that online-based VCT learning models influence students' affective learning outcomes in historical learning.

Keywords: VCT Learning Model, online learning, affective learning results
\end{abstract}

\begin{abstract}
Abstrak
Peningkatan mutu pendidikan didasari atas pembentukan kualitas pembelajaran dan perkembangan teknologi. Kualitas pembelajaran sangat ditentukan oleh kompetensi guru dalam mengelola kelas. Pembelajaran daring dengan berbagai fitur dan aplikasi inilah bisa menjadi alternatif yang tepat bagi kemudahan guru dan siswa untuk tetap berinteraksi tanpa harus bertatap muka pada masa Covid-19. Model pembelajaran VCT dengan berbasis daring dapat memberikan daya kritis-kreatif, menumbuhkan sikap positif, minat, dan nilai pada siswa dalam pembelajaran sejarah. Oleh karenanya tujuan penelitian ini adalah untuk mengetahui pengaruh model pembelajaran Value Clarification Technique berbasis daring terhadap hasil belajar afektif siswa sejarah. Metode penelitian menggunakan metode kuantitatif dengan rancangan quasi eksperimen. Populasi dalam penelitian ini adalah seluruh siswa kelas XI SMA Negeri 9 Kota Bogor. Sedangkan teknik pengambilan sampel yaitu purposive sampling yang terbagi dua kelas menjadi kelompok eksperimen (XI IPA 3) dan kelompok kontrol (XI IPA 1). Metode pengumpulan data adalah metode tes pilihan ganda. Hasil dari penelitian ini menunjukkan bahwa model pembelajaran VCT berbasis daring berpengaruh terhadap hasil belajar afektif siswa dalam pembelajaran sejarah.
\end{abstract}

Kata Kunci : Model Pembelajaran VCT, pembelajaran daring, hasil belajar afektif

Social, Humanities, and Education Studies (SHEs): Conference Series https://jurnal.uns.ac.id/shes

p-ISSN 2620-9284

e-ISSN 2620-9292 


\section{PENDAHULUAN}

Pembentukan kualitas sumber daya manusia menjadi faktor penting kemajuan pendidikan. Sumberdaya manusia yang sangat potensial berperan besar dalam mewujudkan kehidupan bangsa yang cerdas dan kreatif sehingga mampu bersaing secara global. Hal tersebut sebagai tuntutan dari tujuan standar nasional pendidikan Indonesia yaitu mencerdaskan kehidupan bangsa. Tuntutan tersebut menjadikan motivasi serta tolak ukur positif dalam menjalankan proses pembelajaran yang baik dan berkompeten di dalam kelas. Oleh karenanya kualitas pembelajaran akan sangat tergantung pada sumber daya manusia seperti guru.

Kompetensi guru sebagai pendidik akan menjadi sorotan penting dalam pelaksanaan pembelajaran dan proses mencerdaskan bangsa (Siswinarti, 2019). Harapan seorang guru adalah apa yang diajarkan dapat diterima dan dimengerti, agar menjadi bekal untuk diimplementasikan kepada anak didiknya dalam kehidupan seharihari.

Pembelajaran pada satuan pendidikan diselenggarakan secara interaktif, inspiratif, menyenangkan, menantang, memotivasi peserta didik untuk berpartisipasi aktif serta memberikan ruang yang cukup bagi perkembangan fisik, minat, mental serta psikologis siswa (M. Nur Mannan, Achmad Sopyan, 2015). Dalam kurikulum 2013, sangat jelas bagaimana pembelajaran harus memusatkan pada keaktifan siswa untuk berfikir dan berpendapat serta membatasi peran guru secara berlebihan dalam menyampaikan materi. Pembelajaran yang seperti itu seharusnya terjadi pada semua mata pelajaran pada jenjang sekolah menengah atas termasuk mata pelajaran Sejarah. Sejarah adalah cabang ilmu yang mengkaji secara sistematis keseluruhan perkembangan proses perubahan dan dinamika kehidupan masyarakat dengan segala aspek kehidupannya yang terjadi di masa lampau (Sardiman, 2015). Proses pembelajaran sejarah di sekolah harus didorong untuk menciptakan situasi yang dapat menumbuh kembangkan kesadaran sejarah (Sayono, 2013). Jadi materi dalam pembelajaran sejarah tidak hanya sekedar materi hafalan berupa tanggal, tahun atau tokoh, tetapi seharusnya banyak memasukkan unsur-unsur kehidupan kemanusiaan beserta pengorbanannya (Hasan, 2012). Dengan begitu, pembelajaran sejarah harus bisa menginspirasi siswa agar tertarik untuk mempelajarinya.

Permasalahan yang terjadi ketika pembelajaran sejarah yang oleh sebagian siswa masih menganggap sebagai pembelajaran yang membosankan karena seolaholah cenderung "hafalan" dan tidak memberikan manfaat karena kajiannya adalah masa lampau (Aman, 2013). Pengaruh metode konvensional seperti ceramah akan sangat terasa seperti menurunnya konsetrasi siswa, minat dan motivasi siswa berkurang terhadap gurunya ataupun mata pelajarannya, serta meningkatnya ketidakaktifan siswa ketika proses pembelajaran berlangsung. Peranan guru yang dominan dan hanya sebagai objek kontrol dalam pembelajaran konvensional membuat pembelajaran sejarah kurang berkesan (Siregar et al., 2019).

Untuk itu seorang guru sejarah dituntut untuk menciptakan suatu pembelajaran yang dapat mengaktifkan siswa, dan menarik minat siswa untuk menyukai pelajaran sejarah. Menariknya adalah pembelajaran sejarah menjadi mata pelajaran penting karena berkaitan tentang internalisasi nilai-nilai karakter, moral, dan sikap yang diambil dari peristiwa masa lalu. Guru sejarah tidak hanya mengajarkan siswa bagaimana mereka memahami peristiwa sejarah, tetapi juga bagaimana guru sejarah menumbuhkan pendidikan karakter siswa termasuk dalam hal bekerjasama agar dapat menghadapi tantangan global dan sosial yang terjadi. Keberhasilan proses pembelajaran sejarah 
dipengaruhi oleh model pembelajaran yang dilakukan guru. Maka ada berbagai macam model pembelajaran nilai-nilai yang dapat digunakan untuk mengembangkan sikap dan karakter siswa, salah satunya adalah model pembelajaran (Value Clarification Technique) VCT.

Menurut Djahiri sendiri (dalam Sutaryanto, 2016) menjelaskan bahwa Value Clarification Technique (VCT) merupakan sebuah cara bagaimana menanamkan dan menggali atau mengungkapkan nilai- nilai tertentu dari diri siswa. Sedangkan menurut Sanjaya (2008) adalah teknik mengklarifikasi nilai (Value Clarification Techique) sering disingkat VCT dapat diartikan sebagai teknik pengajaran untuk membantu siswa dalam mencari dan menentukan suatu nilai yang dianggap baik dalam menghadapi suatu persoalan melalui proses menganalisis nilai yang sudah ada dan tertanam dalam diri siswa.

Model Value Clarification Technique (VCT) sangat tepat diterapkan pada pembelajaran sejarah karena pembelajaran sejarah bertugas menanamkan nilai-nilai karakter melalui materi-materinya. Selain itu model VCT mampu mengantar siswa mempunyai keterampilan atau kemampuan menentukan nilai-nilai hidup yang tepat sesuai dengan tujuan hidupnya dan menginternalisasikannya sehingga nilai-nilai menjadi pedoman dalam bertingkah atau bersikap.

Model pembelajaran VCT memiliki keunggulan bila dibandingkan model pembelajaran yang lain, diantaranya a) nilai dan moral dapat dipahami dan ditanamkan pada diri siswa, b) guru dengan mudah dapat menyampaikan makna/pesan nilai/ moral pada isi materi pelajaran, c) siswa mampu mengklarifikasi dan menilai kualitas nilai moral pada dirinya dan nilai yang ada pada orang lain, d) potensi diri pada siswa terutama mengembangkan potensi sikap dapat terbentuk dengan mudah, serta e) memberi gambaran nilai moral yang patut diterima dan menuntun serta memotivasi untuk hidup layak dan bermoral tinggi (Taniredja et al., 2012).

Berkaitan dengan penelitian tentang penerapan model pembelajaran VCT, ada beberapa penelitian yang telah dilakukan, seperti Mosconi, Jacqueline \& Emmett, Judith, Ed.D. (2003) dalam penelitiannya menyimpulkan bahwa pembelajaran klarifikasi nilai efektif untuk membantu dalam memahami nilai-nilai, karir masa depan, dan cara-cara mencapai kesuksesan. Selain itu ada penelitian dari Byford, Jeff \& Russell, William B (2009) menyimpulkan bahwa penggunaan teknik diskusi klarifikasi nilai untuk pembelajaran ilmu sosial terbukti sebagai metode yang berharga untuk meningkatkan kesadaran siswa dalam bermasyarakat dan membantu siswa untuk mengembangkan dan mempermudah pemahaman tentang isu tertentu, meningkatkan critical thinking skill, serta meningkatkan keterampilan interpersonal. Ada juga penelitian dari Ninis Khairunisa yang membuktikan bahwa melalui model pembelajaran VCT, memaparkan bahwa siswa menjadi lebih memahami tentang masalah sosial dan nilai-nilai sosial dan membuat pembelajaran IPS lebih bermakna serta menanamkan nilai-nilai kepedulian social secara logis (Khairunisa, 2017). Jadi bila disimpulkan dari hasil penelitian terdahulu bahwa model VCT dapat menjadi alternatif yang cocok untuk penanaman karakter siswa melalui kegiatan pembelajaran khususnya pembelajaran sejarah, dan bisa menumbuhkan sikap positif dan kepedulian sosial yang bisa diterapkan dalam kehidupan sehari-hari serta siswa mampu menginternalisasikan nilai-nilai positif pada dirinya secara demokratis.

Kreatifitas seorang guru sejarah dalam mengelola kelas dengan mempraktikkan dan mengembangkan model pembelajaran aktif, kreatif serta menanamkan nilai-nilai dan karakter kepada siswa haruslah menjadi sesuatu yang patut kita hargai. Para guru berusaha memberikan yang terbaik untuk anak didiknya. Usaha tersebut harus diimbangi dengan keahlian dan kemampuan guru beradaptasi dengan teknologi baru dan tantangan global, karena bentuk peningkatan mutu pendidikan akan tergambar pada kualitas pembelajaran dan perkembangan teknologi. Pembelajaran akan terlaksana dengan maksimal apabila didukung dengan media, metode, alat, dan bahan 
yang memadai. Saat ini dunia memasuki era revolusi industri 4.0 yang ditandai dengan meningkatnya teknologi informasi dan komunikasi yang tidak membatasi antara ruang, waktu, manusia, mesin, dan sumber daya lainnya. Perubahan di era ini sangat membantu memudahkan interaksi secara virtual dengan menggunakan konektivitas jaringan internet dan sistem digital.

Apalagi di era pandemi covid 19 saat ini, teknologi komunikasi sangat dibutuhkan di berbagai aspek kehidupan khususnya pendidikan. Pemerintah pun cepat tanggap dengan mengeluarkan surat edaran (SE) pada 18 Maret 2020 sebagai upaya pengurangan penyebaran Covid-19 dengan menunda segala aktivitas di dalam dan di luar ruangan di semua sektor. Selain itu larangan untuk berkerumun, adanya pembatasan sosial (social distancing) dan menjaga jarak fisik (physical distancing), memakai masker serta selalu cuci tangan adalah aturan tegas dari pemerintah dan WHO untuk selalu kita taati demi keselamatan bersama. Pada tanggal 24 maret 2020 Menteri Pendidikan dan Kebudayaan Republik Indonesia juga mengeluarkan Surat Edaran Nomor 4 Tahun 2020 Tentang Pelaksanaan Kebijakan Pendidikan Dalam Masa Darurat Penyebaran COVID. Surat Edaran tersebut menjelaskan bahwa pembelajaran daring atau jarak jauh mulai diberlakukan dalam proses belajar di rumah dengan tujuan agar memberikan pengalaman belajar yang bermakna bagi siswa (Dewi, 2020).

Pembelajaran daring pada era pandemi ini semakin popular setelah diberlakukannya social distancing sebagai langkah terbaik dalam mencegah penularan Covid-19 (Stein, 2020). Pembelajaran daring menurut Moore, Dickson-Deane, \& Galyen(2011) merupakan pembelajaran yang menggunakan jaringan internet dengan konektivitas, fleksibilitas, dan aksesbilitas. Hal ini berdasar pula pada penelitian yang pernah dikakukan oleh Zhang (2004) bahwasanya penggunaan internet dan teknologi multimedia mampu merombak cara penyampaian pengetahuan dan dapat menjadi alternatif pembelajaran yang dilaksanakan dalam kelas tradisional. Dengan pembelajaran daring siswa akan sangat leluasa untuk belajar kapanpun dan dimanapun tanpa dibatasi waktu. Beberapa aplikasi dan fitur banyak dipergunakan agar memudahkan komunikasi dan interaksi antara guru dan siswa seperti google classroom, video converence, telepon, live chat instagram, zoom maupun melalui whatsapp group. Tuntutan dunia pendidikan melalui pembelajaran secara daring sudah dilakukan beberapa tahun terakhir ( $\mathrm{He}$ et al., 2014). Bahkan menurut Pangondian (2019) pembelajaran daring merupakan bagian dari pembelajaran di era revolusi industri 4.0.

Jika penguasaan kelas sudah menjadi sesuatu yang wajib dilakukan oleh guru, maka dalam situasi darurat pandemic Covid-19 seperti ini guru bisa menggunakan berbagai metode pembelajaran yang dikombinasikan dengan pembelajaran secara daring tanpa harus bertatap muka, misalnya model pembelajaran VCT berbasis daring. Pembelajaran ini bisa menjadi inovasi pendidikan untuk menjawab tantangan akan ketersediaan sumber belajar yang variatif dan menjadi alternatif kemudahan guru dan siswa untuk tetap berinteraksi melalui penggunaan aplikasi internet secara maksimal.

Model pembelajaran VCT berbasis daring akan berfokus pada hasil belajar siswa pada ranah afektif. Hal ini dikarenakan ketercapaian siswa dalam ranah afektif merupakan hal penting dalam membentuk karakteristik siswa khususnya pada pembelajaran sejarah. Ranah afektif ini memunculkan kecenderungan berperilaku sesuai nilai target pembelajaran seperti peduli, kerja keras, disiplin, jujur, dan terbuka (Sulistyawati \& Zuchdi, 2016). Hasil belajar ranah afektif juga akan mempengaruhi sikap dan minat yang positif siswa terhadap suatu pembelajaran. 
Berdasarkan Journal of Geoscience Education diungkapkan bahwa proses pembelajaran afektif bisa melibatkan dan memotivasi siswa untuk tertarik, berminat, dan bersikap positif melalui penggunaan model dengan komponen teoritis, motivasi, dan emosi terhadap pembelajaran geosains (van der Hoeven Kraft et al., 2011). Kemudian ada penelitian dari Vicki Worrel, Collen Evans dan Susan Kovar (2002) yang mengungkapkan bahwa guru olahraga harus memberikan contoh sikap yang baik sehingga siswa memiliki tanggung jawab dan motivasi yang baik terhadap pembelajaran jasmani (olahraga). Ini merupakan langkah yang tepat untuk meningkatkan hasil belajar ranah afektif siswa secara optimal. Selain itu penelitian dalam Journal of Physical Education yang menyebutkan bahwa para guru perlu memposisikan pembelajaran afektif sebagai tujuan utama pengajaran mereka (pelajaran jasmani khususnya) untuk membantu siswa belajar menghargai kontribusi mereka sendiri dan orang lain, menjadi lebih mandiri, menyesuaikan pengajaran teman sebaya dengan kebutuhan mereka sendiri dan orang lain, dan memikirkan kemampuan dalam hal kontribusi (Casey \& Fernandez-rio, 2019).

Berdasarkan uraian di atas, dapat diketahui begitu pentingnya peran model VCT berbasis daring untuk meningkatkan hasil belajar afektif. Penggunaan model pembelajaran VCT berbasis daring, diharapkan dapat memberikan kontribusi terhadap pengembangan kualitas pembelajaran sejarah. Selain itu penelitian ini juga dapat bermanfaat bagi guru dalam merancang dan menerapkan pembelajaran sejarah yang inovatif berdasarkan kemampuan penguasaan teknologi.

Tujuan penelitian ini yaitu untuk mengetahui perbedaan hasil belajar ranah afektif antara kelompok siswa yang belajar menggunakan model pembelajaran VCT dengan kelompok siswa yang belajar menggunakan pembelajaran konvensional. Berdasarkan hal tersebut, maka dilaksanakan penelitian yang berjudul "Pengaruh Model Pembelajaran VCT (Value Clarification Technique) Berbasis Daring Terhadap Hasil Belajar Afektif dalam Pembelajaran Sejarah Siswa Kelas XI SMA Negeri 9 Bogor". Penelitian ini merupakan sebuah tantangan besar bagi peneliti dengan segala keterbatasan yang ada dan senantiasa mematuhi protokol kesehatan di saat darurat pandemic Covid-19 ini.

\section{METODE}

Metode penelitian yang akan digunakan dalam penelitian ini adalah metode penelitian kuantitatif dengan rancangan quasi eksperimen. Sedangkan desain penelitian yang digunakan dalam penelitian eksperimen ini adalah Nonequivalent Control Group Design (Reichardt \& Mark, 2015). Di dalam desain ini, baik kelompok eksperimen maupun kelompok kontrol dibandingkan, kendati kelompok tersebut dipilih dan ditempatkan tanpa melalui random.

Populasi dalam penelitian ini adalah keseluruhan siswa kelas XI di SMA Negeri 9 Kota Bogor yang berjumlah 320 siswa. Pengambilan sampel pada penelitian ini berdasarkan pada teknik pengambilan purposive sampling, yaitu teknik sampling dengan tidak berdasarkan random, tetapi adanya pertimbangan-pertimbangan tertentu di dalam pengambilan sampelnya untuk tujuan tertentu (Robinson, 2014). Perihal pengertian teknik sampling tersebut serta indikasi penggunannya, maka purposive sampling lebih tepat digunakan apabila melihat situasi darurat masa pandemic covid 19 saat ini dimana sekolah harus belajar secara daring. Pembagian dua kelompok yaitu kelas eksperimen dan kelas kontrol ini dipilih tanpa acak. Oleh karena itu ditentukan kelas XI IPA-3 sebagai kelompok eksperimen dan kelas XI IPA-1 sebagai kelompok kontrol.

Pelaksanaan penelitian ini terdiri dari tiga tahap yakni tahap persiapan, tahap pelaksanaan, dan tahap pelaporan. Tahap persiapan terdiri dari merancang perangkat pembelajaran dan instrument penelitian, mengonsultasikan perangkat pembelajaran dan instrumen dengan pembimbing dan pakar, menguji instrumen penelitian, melakukan analisis uji instrumen, merevisi instrumen penelitian yang telah dilakukan. Pada tahap 
pelaksanaan pertemuan diadakan sebanyak empat kali secara online melalui aplikasi zoom, google meet dan google form. Tiga kali pertemuan untuk memberikan treatment dan 1 kali pertemuan untuk pemberian posttest dengan menggunakan aplikasi google form. Pertemuan secara online ini dilakukan hanya seminggu sekali sesuai jadwal yang ditentukan sekolah melihat kondisi pandemi seperti ini. Dalam tahap ini adalah memberikan pelakuan model pembelajaran VCT berbasis daring pada kelas eksperimen dan pembelajaran konvensional pada kelas kontrol, kemudian mengadakan posttest pada kelas eksperimen dan kelas kontrol. Lalu pada tahap pelaporan dengan melakukan analisis data dilanjutkan dengan pengujian hipotesis sesuai data yang diperoleh dan menyusun laporan penelitian sesuai dengan analisis data yang didapatkan.

Model pembelajaran VCT berbasis daring sebagai variabel bebas dan hasil belajar afektif sejarah sebagai variabel terikat. Metode pengumpulan data dalam penelitian ini adalah metode tes, menggunakan tes objektif tipe pilihan ganda. Siswa yang menjawab benar diberi skor 1 dan untuk siswa yang menjawab salah mendapat skor 0 . Setelah itu, penyusunan instrument yang baik harus dilakukan uji validitas, uji reliabilitas, uji tingkat kesukaran, dan uji daya beda tes terlebih dahulu. Uji validitas isi dilakukan dengan cara konsultasi kepada dua pakar terkait dengan soal hasil belajar afektif sejarah dengan hasil perhitungan 1,00 kategori sangat baik. Berdasarkan hasil uji dengan jumlah 39 tes didapatkan 2 tes tidak valid dan 37 butir tes valid, uji reliabilitas tes dengan hasil 0,9079 dengan kriteria sangat tinggi, uji daya beda tes dengan hasil 0,34 dengan kriteria cukup baik dan uji tingkat kesukaran tes dengan hasil 0,68 dengan kriteria sedang. Analisis data yang digunakan adalah analisis statistik deskriptif dan statistik inferensial melalui uji-t.

HASIL DAN PEMBAHASAN

Data hasil penelitian ini diperoleh dari skor hasil postest belajar afektif sejarah sebagai akibat dari penerapan model pembelajaran VCT berbasis daring pada kelompok eksperimen dan pembelajaran konvensional pada kelompok kontrol. Pada kelompok eksperimen yang berjumlah 36 orang siswa mendapatkan skor tertinggi adalah 30 dan skor terendah adalah 14. Jika dideskripsikan skornya yaitu mean $(M)=24,36$, median $(\mathrm{Md})=25,2$ modus (Mo) $=27$, varians $\left(s^{2}\right)=20,91$, dan standar deviasi $(s)=4,57$. Data hasil tes belajar afektif kelompok eksperimen disajikan ke dalam bentuk polygon seperti pada gambar 1.

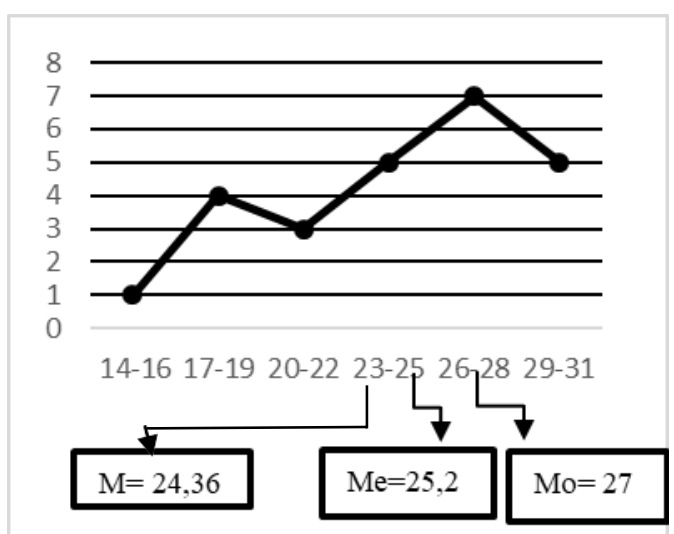

\section{Gambar 1. Kurva Poligon Hasil Belajar Afektif Sejarah Kelompok Eksperimen}

Berdasarkan kurva polygon diatas, diketahui modus lebih besar dari median dan median lebih besar dari mean (Mo>Md $>M$ ) yaitu 27>25,2>24,36, sehingga kurva diatas adalah kurva juling negatif. Artinya skor yang diperoleh. 
adalah cenderung tinggi.

Sedangkan data hasil belajar afektif sejarah pada kelompok kontrol dapat disajikan ke dalam bentuk kurva polygon seperti pada gambar 2.

Gambar 2. Kurva Poligon Hasil Belajar Afektif Sejarah Kelompok Kontrol



Berdasarkan kurva poligon di atas, dapat diketahui modus lebih kecil dari median dan median lebih kecil dari mean $\mathrm{Mo}<\mathrm{Md}<\mathrm{M}(16,04<16,39<16,57)$ sehingga kurva yang terbentuk adalah kurva juling positif. Artinya, skor yang diperoleh cenderung rendah.

Berdasarkan analisis data yang dilakukan dapat disajikan hasil uji normalitas sebaran data hasil belajar afektif Sejarah kelompok eksperimen dan kelompok pada Tabel 1.

Tabel 1. Hasil Uji Normalitas Sebaran Data Skor Hasil Belajar Afektif Sejarah

\begin{tabular}{lllll} 
No. & $\begin{array}{l}\text { Kelompok Data Hasil } \\
\text { Belajar Afektif }\end{array}$ & $X^{2}$ & $\begin{array}{l}\text { Nilai Kritis dengan } \\
\text { Taraf } \\
5 \%\end{array}$ & Signifikansi \\
& & & $5 \%$ & \\
\hline 1. & Kelompok Eksperimen & 6,051 & 7,815 & Normal \\
2. & Kelompok Kontrol & 4,78 & 5,59 & Normal \\
\hline
\end{tabular}

Berdasarkan hasil perhitungan menggunakan rumus Chi-Kuadrat, diperoleh bahwa data skor hasil belajar afektif sejarah kelompok eksperimen dan kelompok kontrol berdistribusi normal.

Pada penelitian ini, uji homogenitas dilakukan terhadap varians antarkelompok eksperimen dan kelompok kontrol. Uji yang digunakan adalah uji $\mathrm{F}$ dengan kriteria data homogen jika $F_{\text {hitung }}<\mathrm{F}_{\text {tabel. }}$ Rekapitulasi hasil uji homogenitas varians antarkelompok eksperimen dan kelompok kontrol disajikan pada Tabel 2.

Tabel 2. Hasil Uji Homogenitas Sebaran Data Skor Hasil Belajar Afektif Sejarah

\begin{tabular}{|c|c|c|c|c|c|}
\hline No. & Sumber Data & Varians & F hitung & $\begin{array}{l}\text { Ftabel dengan Taraf } \\
\text { Signifikansi } 5 \%\end{array}$ & Status \\
\hline $\begin{array}{l}1 . \\
2 .\end{array}$ & $\begin{array}{l}\text { Kelompok } \\
\text { Eksperimen } \\
\text { Kelompok Kontrol }\end{array}$ & $\begin{array}{l}20,91 \\
15,96\end{array}$ & 1,31 & 2,12 & Homogen \\
\hline
\end{tabular}

Berdasarkan Tabel 2 dapat diketahui bahwa varians data hasil belajar afektif Sejarah kelompok eksperimen dan kelompok kontrol homogen. Untuk pembuktian hipotesis yang diajukan dilakukan pengujian dengan menggunakan uji-t sampel independent (tidak berkolerasi) dengan rumus polled varians. 
SHEs: Conference Series 3 (2) (2020) 221- 232

Adapun hasil analisis uji-t disajikan pada Tabel 3.

Tabel 3. Rangkuman Hasil Perhitungan Uji-t.

\begin{tabular}{llllllll}
\hline Data & Kelompok & $N$ & Mean $\left(\begin{array}{llll}X \\
\text { Posttest }\end{array}\right.$ & $s^{2}$ & thitung & $\begin{array}{l}\text { Ttab(t.s } \\
5 \%)\end{array}$ & Kesimpulan \\
\hline Eksperimen & 25 & 24,36 & 20,91 & 60,92 & 2,000 & $\begin{array}{l}\text { thitung }>\text { ttabel } \\
\mathrm{H}_{0} \text { ditolak }\end{array}$ \\
& Kontrol & 21 & 16,57 & 15,96 & & \\
\hline
\end{tabular}

Berdasarkan Tabel 3 dapat diketahui thitung lebh besar dari tabel (thitung $>$ tabel), sehingga $\mathrm{H}_{0}$ ditolak dan $\mathrm{H}_{1}$ diterima. Dengan demikian dapat diinterpretasikan bahwa terdapat perbedaan yang signifikan antara kelompok siswa yang belajar dengan menggunakan model pembelajaran $V C T$ berbasis daring pada kelas XI IPA 3 dan kelompok yang dibelajarkan dengan pembelajaran konvensional pada siswa kelas XI IPA 1.

Berdasarkan penelitian yang dilakukan, terdapat perbedaan rata-rata hasil belajar afektif siswa pada kelompok eksperimen dan kelompok kontrol. Hasil belajar afektif Sejarah kelompok eksperimen lebih tinggi dibandingkan dengan kelompok kontrol. Perbedaan tersebut menunjukkan bahwa model pembelajaran VCT berbasis daring berpengaruh terhadap hasil belajar afektif siswa kelas XI SMAN 9 Kota Bogor dalam pembelajaran sejarah.

\section{SIMPULAN}

Hasil pengujian menunjukan bahwa $t$ hitung=6, $092>t$ tabel $=2,000$ pada taraf signifikansi $5 \%$ berati $\mathrm{H} 0$ ditolak dan $\mathrm{H} 1$ diterima. Berarti kesimpulannya bahwa terdapat perbedaan yang signifikan hasil belajar afektif sejarah antara kelompok siswa yang belajar dengan model pembelajaran VCT berbasis daring dan kelompok siswa yang belajar dengan model pembelajaran konvensional pada siswa kelas XI IPA 3 dan X IPA 1 SMA Negeri 9 Bogor.

Model pembelajaran Value Clarification Technique berbasis daring berpengaruh dalam meningkatkan hasil belajar afektif siswa dalam pembelajaran sejarah Model pembelajaran ini lebih menghargai dan mengedepankan nilai-nilai positif pada diri siswa, memunculkan minat dan ketertarikan terhadap pembelajaran sejarah serta mengubah paradigma siswa untuk terlibat aktif dalam menggali pengetahuan dan pemahaman yang bermakna.

Adapun saran-saran yang perlu disampaikan berdasarkan penelitian yang telah dilakukan adalah 1) Seiring perkembangan teknologi, maka inovasi media, alat, dan model pembelajaran harus lebih bisa dimanfaatkan guru dengan sebaik-baiknya. 2) Pembelajaran daring dengan dimodifikasi menggunakan model VCT ini bisa menjadi alternatif yang baik saat berinteraksi secara virtual.

3) Melalui model VCT berbasis daring ini, guru sejarah lebih mengutamakan proses pembelajaran pada aspek afektif (sikap) kepada siswa karena materi sejarah banyak menanamkan nilai-nilai yang bermakna dari suatu peristiwa sejarah. 4) Kepada kepala sekolah sebaiknya memberikan pelatihan kepada guru-guru mengenai pembelajaran inovatif dan mengupayakan untuk menambah media pembelajaran yang relevan dengan pembelajaran di sekolah atau pembelajaran secara daring. Semoga saran ini bisa memberikan kontribusi 
positif dalam proses penelitian selanjutnya sekaligus bahan rujukan sekolahsekolah yang ingin lebih mengembangkan metode pembelajaran yang inovatif.

\section{DAFTAR PUSTAKA}

Aman, A. (2013). Pengembangan Model Evaluasi Program Pembelajaran Sejarah Di Sma. Jurnal Penelitian Dan Evaluasi Pendidikan, 16(2), 437-456. https://doi.org/10.21831/pep.v16i2.1126

Byford, J., Lennon, S., \& Russell, W. B. (2009). Teaching Controversial Issues in the Social Studies: A Research Study of High School Teachers. The Clearing House: A Journal of Educational Strategies, Issues and Ideas. https://doi.org/10.3200/tchs.82.4.165-170

Casey, A., \& Fernandez-rio, J. (2019). Cooperative Learning and the Affective Domain. 3084. https://doi.org/10.1080/07303084.2019.1559671

Dewi, W. A. F. (2020). Dampak COVID-19 terhadap Implementasi Pembelajaran Daring di Sekolah Dasar. EDUKATIF : JURNAL ILMU PENDIDIKAN. https://doi.org/10.31004/edukatif.v2i1.89

Hasan, S. H. (2012). Pendidikan Sejarah Untuk Memperkuat Pendidikan Karakter. Paramita: Historical Studies Journal, 22(1). https://doi.org/10.15294/paramita.v22i1.1875

He, W., Xu, G., \& Kruck, S. E. (2014). Online is education for the 21st century. Journal of Information Systems Education.

Khairunisa, N. (2017). The Implementation of Value Clarification Technique (VCT) Learning Model to Improve Social Care Character in Social Science Learning. International Journal Pedagogy of Social Studies, 2(1), 153. https://doi.org/10.17509/ijposs.v2i1.8689

Kohlberg, L. (1976). Moral stages and moralization: The cognitive-developmental approach. In Moral development and behavior: Theory, research and social issues. https://doi.org/10.1017/CBO9781107415324.004

M. Nur Mannan, Achmad Sopyan, S. (2015). Pengembangan Perangkat Pembelajaran Berbasis Kearifan Lokal untuk Menembangkan Karakter Positif Siswa SD. Jurnal Inovasi Dan Pembelajaran Fisika.

Moore, J., Dickson-Deane, C., \& Galyen, K. (2011). E-learning, online learning, and distance learning. Internet and Higher Education. https://doi.org/10.1016/j.ineduc.2010.10.001

Mosconi, J., \& Emmett, J. (2003). Effects of a Values Clarification Curriculum on High SchoolStudents' Definitions of Success. Professional School Counseling.

Pangondian, R. A., Santosa, P. I., \& Nugroho, E. (2019). Faktor - Faktor Yang Mempengaruhi Kesuksesan Pembelajaran Daring Dalam Revolusi Industri 4.0. Seminar Nasional Teknologi Komputer \& Sains (SAINTEKS).

Reichardt, C. S., \& Mark, M. M. (2015). Nonequivalent Group Designs. In International Encyclopedia of the Social \& Behavioral Sciences: Second Edition. https://doi.org/10.1016/B978-0-08-097086-8.44039-0

Robinson, R. S. (2014). Purposive Sampling. In Encyclopedia of Quality of Life and WellBeing Research. https://doi.org/10.1007/978-94-007-0753-5_2337

Sardiman, S. (2015). Menakar Posisi Sejarah Indonesia pada Kurikulum 2013. ISTORIA: Jurnal Pendidikan Dan IImu Sejarah. https://doi.org/10.21831/istoria.v11i2.7555

Sayono, J. (2013). Pembelajaran Sejarah Di Sekolah: Dari Pragmatis Ke Idealis. Jurnal Sejarah Dan Budaya, 7(1), 109-123. http://journal.um.ac.id/index.php/sejarah-danbudaya/article/view/4733

Siregar, E., Mulyono, M., Asmin, A., Mukhtar, M., \& Firdaus, M. (2019). Differences in Problem Solving Capabilities among Students Given a ProblemBased Learning Blended Learning with Conventional Learning. American Journal of Educational Research, 7(11), 755-763. https://doi.org/10.12691/education-7-113 
Siswinarti, P. R. (2019). PENGARUH MODEL PEMBELAJARAN VALUE CLARIFICATION TECHNIQUE BERMEDIAKAN VIDEO TERHADAP HASIL BELAJAR PKN. Jurnal IImiah Pendidikan Profesi Guru. https://doi.org/10.23887/jippg.v2i1.18084

Stein, R. A. (2020). COVID-19 and rationally layered social distancing. In International Journal of Clinical Practice. https://doi.org/10.1111/ijcp.13501

Sulistyawati, N., \& Zuchdi, D. (2016). IMPLEMENTASI TEKNIK PEMBELAJARAN KOLABORATIF DENGAN VARIASI MEDIA UNTUK PENINGKATAN HASIL BELAJAR DI SMPN 2 KALIJAMBE. Harmoni Sosial: Jurnal Pendidikan IPS. https://doi.org/10.21831/hsjpi.v3i1.9694

Sutaryanto, S. (2016). Penerapan Model Value Clarification Technique (Vct) Berbantuan Film Dokumenter Dalam Menanamkan Nilai Nasionalisme Dan Meningkatkan Hasil Belajar Pada Siswa Sekolah Dasar. Premiere Educandum: Jurnal Pendidikan Dasar Dan Pembelajaran, 5(02), 237-252. https://doi.org/10.25273/pe.v5i02.287

Taniredja, T., Afandi, M., \& Faridli, E. M. (2012). The appropriate Pancasila education contents to implant lofty values for Indonesian students. Educare: International Journal for Educational Studies.

van der Hoeven Kraft, K. J., Srogi, L., Husman, J., Semken, S., \& Fuhrman, M. (2011). Engaging students to learn through the affective domain: A new framework for teaching in the geosciences. Journal of Geoscience Education. https://doi.org/10.5408/1.3543934a

Worrell, V., Evans-Fletcher, C., \& Kovar, S. (2002). Assessing the Cognitive and Affective Progress of Children. Journal of Physical Education, Recreation \& Dance, 73(7), 29-34. https://doi.org/10.1080/07303084.2002.10607844

Zhang, D., Zhao, J. L., Zhou, L., \& Nunamaker, J. F. (2004). Can e-learning replace classroom learning? In Communications of the ACM. https://doi.org/10.1145/986213.986. 
SHEs: Conference Series 3 (2) (2020) 221- 232 